\title{
Different effects of SGLT2 inhibitors according to the presence and types of heart failure in type 2 diabetic patients
}

\author{
In-Chang Hwang ${ }^{1,2}$, Goo-Yeong Cho ${ }^{1,2^{*}}$ (D) Yeonyee E. Yoon ${ }^{1,2}$, Jin Joo Park ${ }^{1,2}$, Jun-Bean Park ${ }^{2,3}$, Seung-Pyo Lee ${ }^{2,3}$, \\ Hyung-Kwan Kim ${ }^{2,3}$, Yong-Jin Kim ${ }^{2,3}$ and Dae-Won Sohn ${ }^{2,3}$
}

\begin{abstract}
Background: The effects of sodium-glucose cotransporter 2 inhibitor (SGLT2i) on cardiac function are not fully understood. We investigated the changes in cardiac function in diabetic patients according to the presence and types of heart failure (HF).

Methods: We retrospectively identified 202 diabetic patients who underwent echocardiography before, and 6 to 24 months after the initiation of SGLT2i. After propensity score matching with diabetic patients without SGLT2i, the study population ( $n=304$ ) were categorized into group 1 (without HF nor SGLT2i; $n=76$ ), group 2 (without HF and received SGLT2i; $n=78$ ), group 3 (with HF but without SGLT2i; $n=76$ ), and group 4 (with HF and received SGLT2i; $\mathrm{n}=74$ ). Changes in echocardiographic parameters were compared between these 4 groups, and between $\mathrm{HF}$ patients with reduced versus preserved ejection fraction (EF).
\end{abstract}

Results: After a median 13 months of follow-up, HF patients with SGLT2i showed a significant decrease in left ventricular end-diastolic dimension (LV-EDD; from $57.4 \mathrm{~mm}$ [50.0-64.9] to $53.0 \mathrm{~mm}$ [48.0-60.0]; $\mathrm{p}<0.001$ ) and improvement in LV-EF (from 36.1\% [25.6-47.5] to 45.0\% [34.8-56.3]; $p<0.001$ ). LV mass index and diastolic parameters also showed improvements in HF patients with SGLT2i. The SGLT2i-induced improvements in cardiac function were more prominent in $\mathrm{HF}$ patients than those without $\mathrm{HF}$, and in HFrEF patients than HFpEF patients.

Conclusions: Use of SGLT2i improved cardiac function in diabetic patients, regardless of the presence of HF. The improvements were more prominent in HF patients, especially in those with HFrEF. These improvements in cardiac function would contribute to the clinical benefit of SGLT2i.

Keywords: Heart failure, Diabetes, Echocardiography, Sodium-glucose cotransporter 2 inhibitor, SGLT2 inhibitor

\section{Background}

Sodium glucose co-transporter 2 (SGLT2) is the major cotransporter involved in glucose reabsorption in the kidney, and the inhibition of SGLT2 has been established as a novel therapeutic measure for diabetic control. In particular, the SGLT2 inhibitors (SGLT2i) have

\footnotetext{
*Correspondence: cardioch@snu.ac.kr

${ }^{1}$ Cardiovascular Center and Department of Internal Medicine, Seoul National University Bundang Hospital, Seongnam, Gyeonggi, South Korea Full list of author information is available at the end of the article
}

demonstrated robust benefits in terms of the prevention of heart failure (HF) and the reduction in cardiovascular mortality, which was the first evidence for prevention of major cardiovascular events by anti-diabetic medications. Several large-scale trials showed concordant results of SGLT2i for HF prevention [1-3].

Adding to the glucose lowering effect of SGLT2i, several glucose-independent mechanisms have been suggested for HF prevention: preload and afterload reduction by natriuresis and osmotic diuresis, improvement in cardiac metabolism and bioenergetics, reduced 
myocardial necrosis and fibrosis, and alteration in adipokines [4]. These hypotheses were further supported by the recently published trial of dapagliflozin, the Dapagliflozin and Prevention of Adverse-outcomes in Heart Failure (DAPA-HF) trial, which extended the benefits of SGLT2i to those with HF with reduced ejection fraction (HFrEF) even in the absence of diabetes.

Despite the well-established clinical benefits of SGLT2i, only limited studies on the changes in cardiac function by SGLT2i have been made so far. Furthermore, it is unclear whether the cardiovascular benefits of SGLT2i would be similar between the diabetic patients with versus without $\mathrm{HF}$, and between those with HFrEF versus HFpEF. We aimed to compare the SGLT2i-induced changes in cardiac function and geometry assessed by echocardiography in type 2 diabetic patients according to the presence and types of HF, using a retrospective cohort.

\section{Methods}

\section{Patients}

This retrospective (cohort) study was carried out according to the principles of the Declaration of Helsinki and was approved by the Clinical Research Institute of Seoul
National University Bundang Hospital (approved on March 11 2019; IRB No. B-1903-531-105).

From October 2014 to April 2019, we retrospectively identified 2819 patients with type 2 diabetes who visited Seoul National University Bundang Hospital and were prescribed with SGLT2i (1679 patients prescribed with dapagliflozin; 1131 with empagliflozin; and 9 with ipragliflozin) (Fig. 1). Comorbidities of patients were determined from the electronic medical record. Patients without echocardiography or with only 1 echocardiography were excluded. Among the patients with 2 or more echocardiograms, those with the interval of two echocardiograms $<6$ months or $>24$ months were excluded. Patients for whom echocardiograms were performed during hospitalization for acute HF were also excluded. Using these exclusion criteria, 8039 diabetic patients without SGLT2i prescription were identified.

For the patients with SGLT2i prescription, those with all echocardiograms performed before, but not after, the initial SGLT2i prescription were excluded. Patients with all echocardiograms performed after, but not before, the initial SGLT2i prescriptions were also excluded. In addition, patients with no

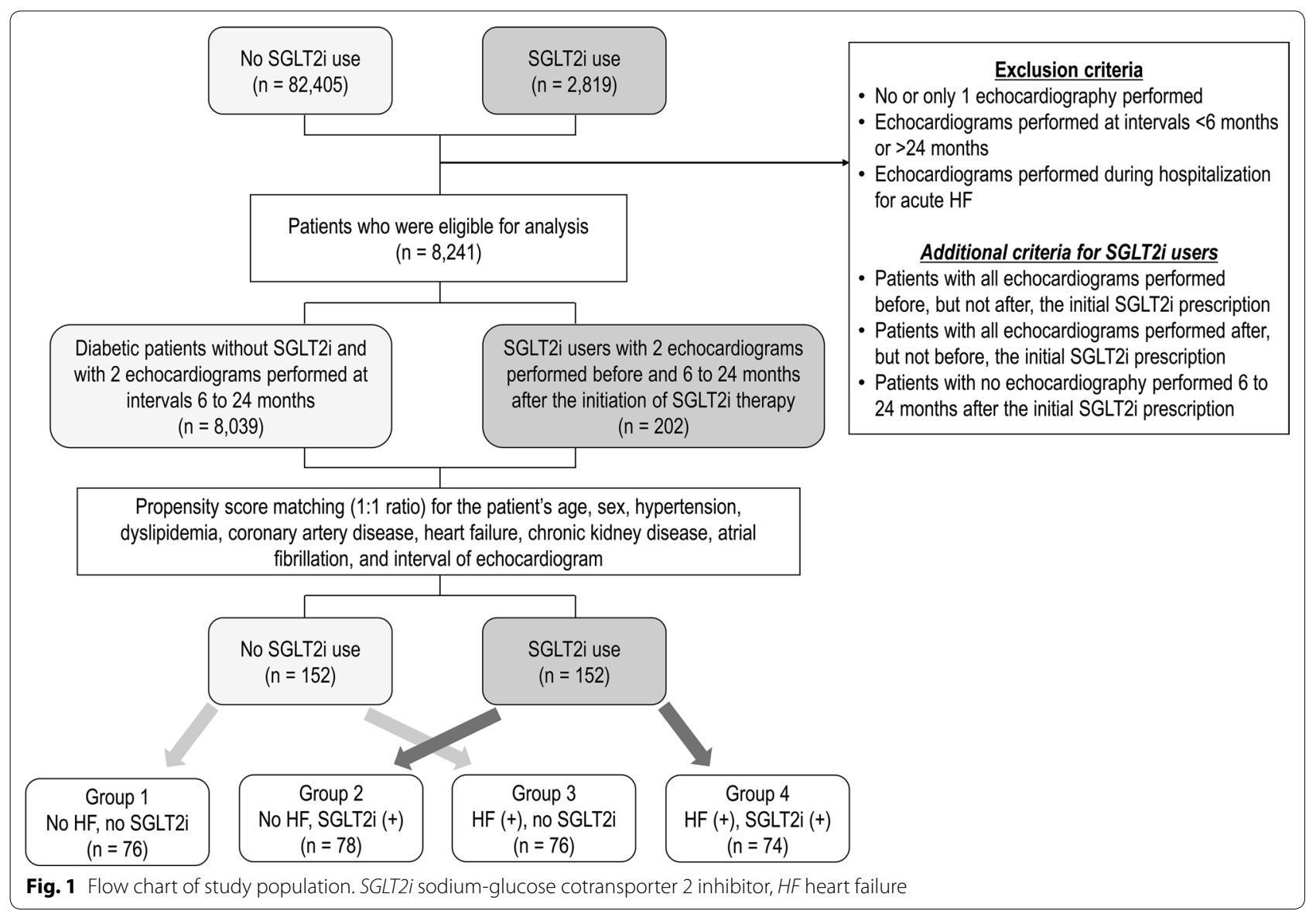


echocardiography performed 6-24 months after the initial SGLT2i prescription were excluded. After exclusion, 202 diabetic patients for whom SGLT2i were prescribed, and for whom the baseline echocardiography was performed before the initial SGLT2i prescription and the follow-up echocardiography was performed at 6-24 months after the initial SGLT2i prescription were identified.

Using the propensity score matching with 1:1 ratio for age, sex, hypertension, dyslipidemia, coronary artery disease, HF, chronic kidney disease, atrial fibrillation, and interval of echocardiogram, the 202 diabetic patients with SGLT2i prescription were matched to 8039 diabetic patients without SGLT2i (Additional file 1: Table S1). The definition of coronary artery disease was a presence of $\geq 50 \%$ diameter-stenosis on invasive coronary angiography or computed tomography angiography, a presence of perfusion decrease on myocardial perfusion imaging, or a positive result on treadmill test. HF was defined as the presence of New York Heart Association functional class $\geq$ II and elevated $\mathrm{N}$-terminal pro-B-type natriuretic peptide (NT-proBNP; $>125 \mathrm{pg} / \mathrm{mL}$ ) or echocardiographic findings suggestive of HF (left ventricular ejection fraction $[\mathrm{LV}-\mathrm{EF}]<40 \%$, diastolic dysfunction, or other relevant structural heart disease including LV hypertrophy and/or left atrial enlargement), according to the clinical guidelines $[5,6]$. The chronic kidney disease was defined as the glomerular filtration rate $<60 \mathrm{~mL} /$ $\mathrm{min} / 1.73 \mathrm{~m}^{2}$.

The propensity score matching was successful, and a total of 152 diabetic patients on SGLT2i and a total of 152 diabetic patients without SGLT2i were identified (Fig. 1). We categorized the study population into 4 groups divided according to the presence of HF and the prescription of SGLT2i: diabetic patients without HF and without SGLT2i (group 1; $\mathrm{n}=76$ ), diabetic patients without HF and with SGLT2i (group 2; $n=78$ ), diabetic patients with HF but without SGLT2i (group 3; $n=76$ ), and diabetic patients with HF and with SGLT2i (group $4 ; \mathrm{n}=74)$.

\section{Echocardiography and strain analysis}

Results of the baseline and follow-up echocardiography were obtained from the database. Standard techniques were used to obtain M-mode, 2-dimensional, and Doppler measurements in accordance with the guidelines [7]. The LV global longitudinal strain (LV-GLS) measurements were performed by experienced echocardiography specialists in a blinded fashion using TomTec software (Image Arena 4.6, Munich, Germany), according to current guidelines [8]. We took the absolute value $|x|$ of LV-GLS for simpler interpretation.

\section{Study outcomes}

The study outcomes were the changes in echocardiographic parameters of LV geometry (LV end-diastolic dimension [LV-EDD], LV end-diastolic volume [LVEDV], and LV mass index [LV-MI]), systolic function (LV-EF and LV-GLS), and diastolic function (mitral E/e' ratio, and the estimated pulmonary artery systolic pressure $[\mathrm{PASP}])$.

The changes in echocardiographic parameters were compared between the four subgroups divided according to the presence of HF and the SGLT2i prescription. In addition, as a sensitivity analysis, we compared the changes in echocardiographic parameters according to the use of SGLT2i between patients with HF with reduced $\mathrm{EF}$ ( $\mathrm{LV}-\mathrm{EF}<40 \%$ at baseline) and those with $\mathrm{HF}$ with preserved $\mathrm{EF}$ ( $\mathrm{HFpEF}$ ) ( $\mathrm{LV}-\mathrm{EF} \geq 40 \%$ at baseline).

\section{Statistical analysis}

Categorical variables are presented as frequencies and percentages, and continuous variables as means \pm standard deviations (SD) or medians with interquartile ranges (IQR). Group comparisons were performed with student $t$ test or paired $\mathrm{t}$-test for normally distributed data and the Wilcoxon matched pairs test when data were nonnormal. The $\chi^{2}$ test or the Fisher's exact test was used for categorical variables. In order to assess the association between the use of SGLT2i and the improvement LV-EF, we used logistic regression analysis for the $+5 \%$ improvement in LV-EF and for the $+10 \%$ improvement in LV-EF. Multivariable logistic regression analysis with stepwise backward elimination method was performed all variables of $\mathrm{p}$-values $<0.20$ by univariate analyses. All of the statistical analyses were performed using SPSS 21.0 (SPSS Inc, Chicago, Ill) and a p-value $<0.05$ was considered statistically significant.

\section{Results}

\section{Baseline characteristics and candidate predictors}

In total study population, the median age was 66 years (56-74), and 65\% were male (Table 1). Prevalence of comorbidities were not different across the subgroups. Eighty-two percent of patients were on metformin, $60 \%$ were on sulfonylurea, and $69 \%$ were on DPP- 4 inhibitors. The levels of fasting serum glucose and $\mathrm{HbA} 1 \mathrm{c}$ were not different across the subgroups. The median followup interval of the total study population was $13(8-20)$ months, and was not different between the subgroups.

The types and doses of SGLT2i were not different between group 2 vs. 4 (Table 1 and Additional file 1: Table S2). Eighty-three patients (27.3\%) were on 
Table 1 Baseline characteristics

\begin{tabular}{|c|c|c|c|c|c|c|c|}
\hline & $\begin{array}{l}\text { Total study } \\
\text { population } \\
(\mathrm{n}=304)\end{array}$ & $\begin{array}{l}\text { Group } 1 \text { No } \\
\text { HF, no SGLT2i } \\
(n=76)\end{array}$ & $\begin{array}{l}\text { Group } 2 \text { No } \\
\text { HF, SGLT2i }(+) \\
(n=78)\end{array}$ & $\begin{array}{l}\text { p-value } \\
\text { (groups } 1 \\
\text { vs. 2) }\end{array}$ & $\begin{array}{l}\text { Group } 3 \text { HF } \\
(+), \text { no SGLT2i } \\
(n=76)\end{array}$ & $\begin{array}{l}\text { Group } 4 \text { HF } \\
(+), \text { SGLT2i }(+) \\
(n=74)\end{array}$ & $\begin{array}{l}\text { p-value } \\
\text { (groups } 3 \\
\text { vs. 4) }\end{array}$ \\
\hline Age (years) & $66(56-74)$ & $66(58-72)$ & $65(56-72)$ & 0.470 & $67(56-75)$ & $67(54-75)$ & 0.950 \\
\hline Male sex (n, \%) & 198 (65.1\%) & 44 (57.9\%) & $52(66.7 \%)$ & 0.261 & $50(65.8 \%)$ & 52 (70.3\%) & 0.676 \\
\hline $\begin{array}{l}\text { Systolic blood } \\
\text { pressure } \\
\text { (mmHg) }\end{array}$ & $132(118-148)$ & $136(119-148)$ & $134(121-154)$ & 0.832 & $126(113-148)$ & $130(116-143)$ & 0.924 \\
\hline $\begin{array}{l}\text { Diastolic blood } \\
\text { pressure } \\
(\mathrm{mmHg})\end{array}$ & 76 (68-85) & $75(70-81)$ & $78(65-88)$ & 0.876 & 78 (68-85) & $76(68-84)$ & 0.800 \\
\hline $\begin{array}{l}\text { Heart rate (per } \\
\text { minute) }\end{array}$ & 79 (68-91) & $76(66-87)$ & $75(68-83)$ & 0.638 & 83 (68-99) & $83(71-97)$ & 0.635 \\
\hline $\begin{array}{l}\text { NYHA functional } \\
\text { class III/IV }\end{array}$ & $53(17.4 \%)$ & $0(0.0 \%)$ & $0(0.0 \%)$ & N/A & $26(34.2 \%)$ & $27(36.5 \%)$ & 0.771 \\
\hline Hypertension & 149 (49.9\%) & 37 (48.7\%) & 31 (39.7\%) & 0.264 & $43(56.6 \%)$ & 38 (51.4\%) & 0.631 \\
\hline Dyslipidemia & $101(33.2 \%)$ & 25 (32.9\%) & $23(29.5 \%)$ & 0.648 & $27(35.5 \%)$ & $26(35.1 \%)$ & 0.960 \\
\hline $\begin{array}{l}\text { Coronary artery } \\
\text { disease }\end{array}$ & $110(36.2 \%)$ & $26(34.2 \%)$ & 31 (39.7\%) & 0.477 & $27(35.5 \%)$ & $26(35.1 \%)$ & 0.828 \\
\hline $\begin{array}{l}\text { Chronic kidney } \\
\text { disease }\end{array}$ & $36(11.8 \%)$ & $10(13.2 \%)$ & $8(10.3 \%)$ & 0.575 & $9(11.8 \%)$ & $9(12.2 \%)$ & 0.952 \\
\hline Atrial fibrillation & $96(31.6 \%)$ & $13(17.1 \%)$ & 14 (17.9\%) & 0.891 & $36(47.4 \%)$ & $33(44.6 \%)$ & 0.858 \\
\hline \multicolumn{8}{|l|}{ Medications } \\
\hline \multicolumn{8}{|l|}{ Use of SGLT2i } \\
\hline Dapagliflozin & 69 (22.7\%) & $0(0.0 \%)$ & 39 (50.0\%) & N/A & $0(0.0 \%)$ & 29 (39.2\%) & N/A \\
\hline Empagliflozin & $83(27.3 \%)$ & $0(0.0 \%)$ & 39 (50.0\%) & N/A & $0(0.0 \%)$ & 45 (60.8\%) & N/A \\
\hline $\begin{array}{l}\text { Duration of SGLT2i } \\
\text { use (months) }\end{array}$ & - & - & $10(5-15)$ & N/A & - & $10(7-15)$ & $\mathrm{N} / \mathrm{A}$ \\
\hline Statin & $254(83.6 \%)$ & 69 (90.8\%) & $68(87.2 \%)$ & 0.475 & $58(76.3 \%)$ & 59 (79.7\%) & 0.614 \\
\hline Metformin & 249 (81.9\%) & 59 (77.6\%) & 63 (80.8\%) & 0.631 & $61(80.3 \%)$ & 66 (89.2\%) & 0.174 \\
\hline Sulfonylurea & $184(60.5 \%)$ & 38 (50.0\%) & $50(64.1 \%)$ & 0.077 & $45(59.2 \%)$ & $51(68.9 \%)$ & 0.216 \\
\hline DPP-4 inhibitors & $210(69.1 \%)$ & $47(61.8 \%)$ & $56(71.8 \%)$ & 0.189 & $55(72.4 \%)$ & $52(70.3 \%)$ & 0.776 \\
\hline ACE inhibitors & $107(35.2 \%)$ & $20(26.3 \%)$ & $26(33.3 \%)$ & 0.341 & $29(38.2 \%)$ & $32(43.2 \%)$ & 0.526 \\
\hline ARB & $161(53.0 \%)$ & 41 (53.9\%) & $38(48.7 \%)$ & 0.516 & $42(55.3 \%)$ & $40(54.1 \%)$ & 0.882 \\
\hline Beta-blockers & $255(83.9 \%)$ & $58(76.3 \%)$ & $61(78.2 \%)$ & 0.780 & $67(88.2 \%)$ & 69 (93.2\%) & 0.284 \\
\hline MRA & $103(33.9 \%)$ & $9(11.8 \%)$ & $9(11.5 \%)$ & 0.953 & $40(52.6 \%)$ & $45(60.8 \%)$ & 0.312 \\
\hline Diuretics & $179(58.9 \%)$ & $23(30.3 \%)$ & 31 (39.7\%) & 0.218 & $59(77.6 \%)$ & $66(89.2 \%)$ & 0.079 \\
\hline \multicolumn{8}{|c|}{ Baseline laboratory tests } \\
\hline Hemoglobin (g/dL) & $13.8(12.7-15.1)$ & $13.7(12.8-15.0)$ & $14.1(13.1-15.0)$ & 0.368 & $13.7(12.3-15.3)$ & $13.6(12.1-15.3)$ & 0.624 \\
\hline $\begin{array}{l}\text { Serum creatinine } \\
(\mathrm{mg} / \mathrm{dL})\end{array}$ & $0.9(0.8-1.1)$ & $0.9(0.7-1.1)$ & $0.9(0.8-1.1)$ & 0.839 & $1.0(0.8-1.2)$ & $1.0(0.8-1.3)$ & 0.806 \\
\hline $\begin{array}{l}\text { Total cholesterol } \\
\text { (mg/dL) }\end{array}$ & 144.5 (122.5-172.0) & $\begin{array}{l}151.5(127.0- \\
174.0)\end{array}$ & $\begin{array}{l}142.5(119.0- \\
172.0)\end{array}$ & 0.171 & $\begin{array}{l}136.0(119.0- \\
169.0)\end{array}$ & $\begin{array}{l}142.5(120.0- \\
170.0)\end{array}$ & 0.930 \\
\hline $\begin{array}{l}\text { Fasting glucose } \\
\text { (mg/dL) }\end{array}$ & $136.0(117.0-159.0)$ & $\begin{array}{l}138.0(119.0- \\
161.5)\end{array}$ & $\begin{array}{l}138.0(116.0- \\
175.0)\end{array}$ & 0.427 & $\begin{array}{l}129.5(113.5- \\
149.5)\end{array}$ & $\begin{array}{l}132.0(117.0- \\
155.0)\end{array}$ & 0.363 \\
\hline $\mathrm{HbA1c}(\%)$ & $7.1(6.5-8.0)$ & $7.3(6.6-7.8)$ & $7.5(6.6-8.6)$ & 0.095 & $6.8(6.4-7.8)$ & $6.9(6.4-7.7)$ & 0.905 \\
\hline $\begin{array}{l}\text { NT-proBNP } \\
(\mathrm{pg} / \mathrm{mL})\end{array}$ & $\begin{array}{l}447.7(106.9- \\
2432.6)(n=207)\end{array}$ & $\begin{array}{l}100.0(54.8-199.2) \\
(n=30)\end{array}$ & $\begin{array}{l}77.3(32.7-197.8) \\
\quad(n=36)\end{array}$ & 0.858 & $\begin{array}{l}925.6(311.9- \\
3386.1)(n=70)\end{array}$ & $\begin{array}{l}1819.6(547.3- \\
5695.4)(n=71)\end{array}$ & 0.637 \\
\hline \multicolumn{8}{|c|}{ Echocardiographic parameters } \\
\hline LV-EDV (mL) & $92.0(69.0-128.5)$ & $76.0(64.5-96.5)$ & $79.5(65.0-97.0)$ & 0.430 & $111.9(82.5-148.5)$ & $128.5(94.0-169.0)$ & 0.098 \\
\hline LV-ESV (mL) & $41.0(28.9-80.7)$ & $29.6(23.5-42.8)$ & $32.0(25.0-42.0)$ & 0.486 & $69.5(33.0-112.0)$ & $82.5(41.0-125.0)$ & 0.115 \\
\hline LV-EDD (mm) & $50.9(46.5-80.0)$ & $48.0(44.5-50.0)$ & $49.0(45.0-52.0)$ & 0.174 & $56.1(49.5-62.0)$ & $57.4(50.0-64.9)$ & 0.203 \\
\hline LV-ESD (mm) & $35.7(30.0-47.0)$ & $31.0(28.4-35.5)$ & $32.0(28.0-36.0)$ & 0.658 & $44.0(32.5-51.0)$ & $45.4(37.0-54.0)$ & 0.181 \\
\hline LV-EF (\%) & $52.0(35.6-61.1)$ & $60.4(52.4-63.8)$ & $59.4(49.3-63.6)$ & 0.628 & $38.8(28.0-55.9)$ & $36.1(25.6-47.5)$ & 0.094 \\
\hline
\end{tabular}


Table 1 (continued)

\begin{tabular}{|c|c|c|c|c|c|c|c|}
\hline & $\begin{array}{l}\text { Total study } \\
\text { population } \\
(\mathrm{n}=304)\end{array}$ & $\begin{array}{l}\text { Group } 1 \text { No } \\
\text { HF, no SGLT2i } \\
(n=76)\end{array}$ & $\begin{array}{l}\text { Group } 2 \text { No } \\
\text { HF, SGLT2i (+) } \\
(n=78)\end{array}$ & $\begin{array}{l}\text { p-value } \\
\text { (groups } 1 \\
\text { vs. 2) }\end{array}$ & $\begin{array}{l}\text { Group } 3 \text { HF } \\
(+), \text { no SGLT2i } \\
(n=76)\end{array}$ & $\begin{array}{l}\text { Group } 4 \text { HF } \\
(+), \text { SGLT2i (+) } \\
(n=74)\end{array}$ & $\begin{array}{l}\text { p-value } \\
\text { (groups } 3 \\
\text { vs. 4) }\end{array}$ \\
\hline LV-MI $\left(\mathrm{g} / \mathrm{m}^{2}\right)$ & $112.8(91.0-134.7)$ & $99.6(84.1-123.3)$ & $96.6(82.7-114.7)$ & 0.613 & $\begin{array}{l}120.9(101.3- \\
146.5)\end{array}$ & $\begin{array}{l}126.3(111.1- \\
147.3)\end{array}$ & 0.666 \\
\hline LAVI $\left(\mathrm{mL} / \mathrm{m}^{2}\right)$ & $40.3(31.0-56.5)$ & $31.8(28.3-39.9)$ & $34.7(29.5-44.8)$ & 0.081 & $48.2(36.2-68.1)$ & $53.5(41.6-72.3)$ & 0.860 \\
\hline PASP $(\mathrm{mmHg})$ & $28.0(24.4-38.6)$ & $26.2(23.0-29.3)$ & $26.2(22.6-30.0)$ & 0.808 & $32.0(26.2-41.0)$ & $36.4(28.0-54.0)$ & 0.038 \\
\hline E velocity (m/s) & $0.70(0.58-0.87)$ & $0.66(0.59-0.78)$ & $0.63(0.57-0.78)$ & 0.760 & $0.73(0.58-0.87)$ & $0.79(0.63-1.03)$ & 0.030 \\
\hline $\begin{array}{l}\text { Mitral annular } \mathrm{e}^{\prime} \\
\text { velocity }(\mathrm{cm} / \mathrm{s})\end{array}$ & $5.7(4.2-7.2)$ & $6.10(4.80-7.40)$ & $6.00(5.00-7.10)$ & 0.403 & $5.7(4.2-7.2)$ & $5.10(3.70-6.50)$ & 0.167 \\
\hline $\begin{array}{l}\text { Mitral annular s' } \\
\text { velocity }(\mathrm{cm} / \mathrm{s})\end{array}$ & $6.0(4.7-7.5)$ & $6.7(5.4-8.4)$ & $6.6(5.5-7.8)$ & 0.696 & $5.3(4.2-6.7)$ & $5.0(3.8-6.1)$ & 0.377 \\
\hline Mitral E/e' ratio & $12.6(9.3-17.1)$ & $10.8(8.9-14.1)$ & $10.6(9.0-13.5)$ & 0.742 & $13.2(9.8-17.8)$ & $15.6(11.9-24.3)$ & 0.026 \\
\hline LV-GLS (\%) & $12.5(9.5-15.5)$ & $15.2(12.5-16.9)$ & $14.6(12.1-17.0)$ & 0.962 & $10.9(8.4-12.3)$ & $10.3(7.3-12.5)$ & 0.532 \\
\hline $\begin{array}{l}\text { Follow-up interval } \\
\text { (months) }\end{array}$ & $13(8-20)$ & $13(8-21)$ & $12(9-19)$ & 0.091 & $11(7-16)$ & $14(8-21)$ & 0.183 \\
\hline
\end{tabular}

Data are expressed as median with interquartile range (Q1-Q3) or as number (percentage)

HF heart failure, SGLT2i sodium-glucose cotransporter 2 inhibitor, NYHA New York Heart Association, DPP-4 dipeptidyl peptidase-4, ACEi angiotensin converting enzyme inhibitor, $A R B$ angiotensin receptor blocker, MRA mineralocorticoid antagonist, HbA1c hemoglobin A1c, $L V$ left ventricular, EDV end-diastolic volume, ESV endsystolic volume, $E D D$ end-diastolic dimension, ESD end-systolic dimension, EF ejection fraction, $M I$ mass index, LAVI left atrial volume index, PASP pulmonary artery systolic pressure, GLS global longitudinal strain

empagliflozin, and $69(22.7 \%)$ on dapagliflozin. The duration of SGLT2i use was 10 (5-15) months in group 2 , and was 10 (7-15) months in group 4. Use of angiotensin converting enzyme inhibitors (ACEi), angiotensin receptor blocker (ARB), beta-blockers, mineralocorticoid antagonists (MRA), and diuretics were more frequent in patients with HF (groups 3 and 4) compared to those without HF (groups 1 and 2), but were not different according to the use of SGLT2i (groups 1 vs. 2; groups 3 vs. 4). Also, the types of cardioprotective medications (ACEi, ARB, beta-blockers, and MRA) and their changes during follow-up were not different according to the use of SGLT2i. Detailed information on the use of medications are summarized in Additional file 1: Table S2.

\section{Comparison of echocardiographic parameters according to the presence of $\mathrm{HF}$}

At baseline, the patients with HF (groups 3 and 4) had worse echocardiographic parameters compared to those without HF (groups 1 and 2), but there was no difference according to the use of SGLT2i, both in those without HF (groups 1 vs. 2) and in those with HF (groups 3 vs. 4) (Table 1).

At follow-up, the LV geometry showed significant differences according to the use of SGLT2i and to the presence of HF (Fig. 2). In patients without HF, those with SGLT2i treatment showed a small but significant decrease in LV-EDD (from 49.0 [45.0-52.0] to $47.0 \mathrm{~mm}$ [44.0-51.0]; $\mathrm{p}=0.036$ ), but those without SGLT2i did not ( $p$ for interaction $=0.041$ ) (Fig. 2a). In the HF patients, we observed a significant decrease in LV-EDD (from 57.4 [50.0-64.9] to $53.0 \mathrm{~mm}$ [48.0-60.0]; $\mathrm{p}<0.001$ ), as well as LV-MI (from 126.3 [111.1-147.3] to $115.2 \mathrm{~g} / \mathrm{m}^{2}$ [97.0137.8]; $\mathrm{p}=0.026$ ) in SGLT2i treated group, but not in the HF patients without SGLT2i treatment ( $\mathrm{p}$ for interaction $=0.004$ for LV-EDD, $<0.001$ for LV-MI) (Fig. 2a, b).

In patients without HF, the SGLT2i users showed a significant increase in LVEF in group 2 (from 59.4 [49.363.6] to 61.6\% [55.6-65.7]; $\mathrm{p}<0.001$ ) but not in the group 1 (from 60.4 [52.4-63.8] to 60.2\% [52.1-63.3]) (Fig. 2c). Similarly, the LV-GLS was improved in group 2 but not in group 1 (Fig. 2d). In the HF patients, those with SGLT2i treatment (group 4) showed a prominent improvement in LV-EF (from 36.1 [25.6-47.5] to 45.0\% [34.8-56.3]; $\mathrm{p}<0.001$ ) as well as LV-GLS (from 10.3 [7.3-12.5] to $11.4 \%$ [8.4-14.3]; $\mathrm{p}=0.001$ ). The HF patients without SGLT2i (group 3) also demonstrated subtle improvement in LV-EF and LV-GLS, but the improvement in LV-EF was more prominent in the HF patients with SGLT2i treatment (group 4) ( $p$ for interaction $=0.003$ for LV-EF). Multivariable logistic regression analysis showed that the use of SGLT2i was significantly associated with $+5 \%$ improvement in LV-EF (adjusted OR, 2.384; $95 \%$ CI, 1.266-4.448; $\mathrm{p}=0.007$ ) (Table 2 and Additional file 1: Table S3). For $+10 \%$ improvement in LV-EF, the use of SGLT2i (adjusted OR, 2.236; 95\% CI, 1.106-4.521; $\mathrm{p}=0.025)$ and the standard dose of beta-blockers for HF (adjusted OR, 2.849; 95\% CI, 1.126-7.205; $\mathrm{p}=0.027$ ) showed significant associations (Table 2 and Additional file 1: Table S3). We further assessed the changes in LV 
a Changes in LV-EDD

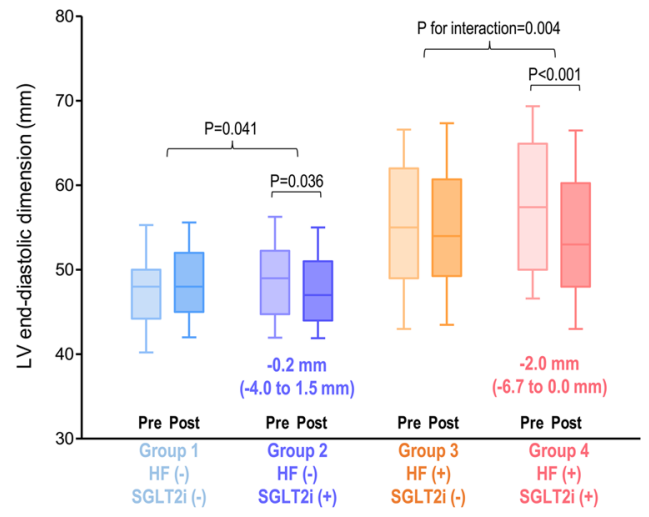

\section{Changes in LV-EF}
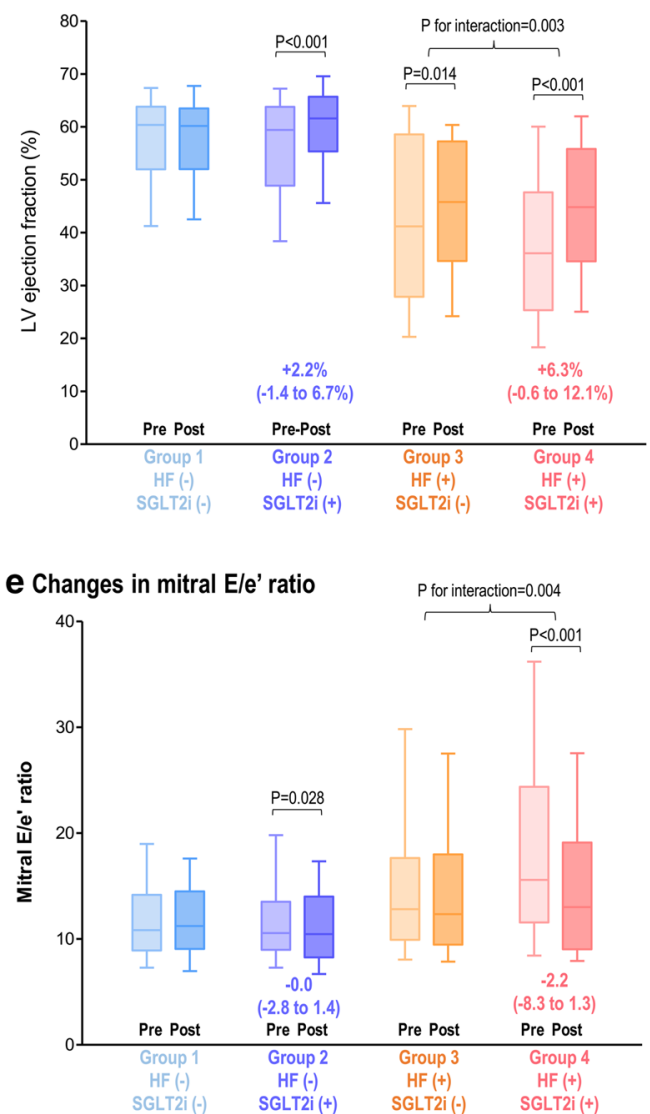

\section{b Changes in LV-MI}

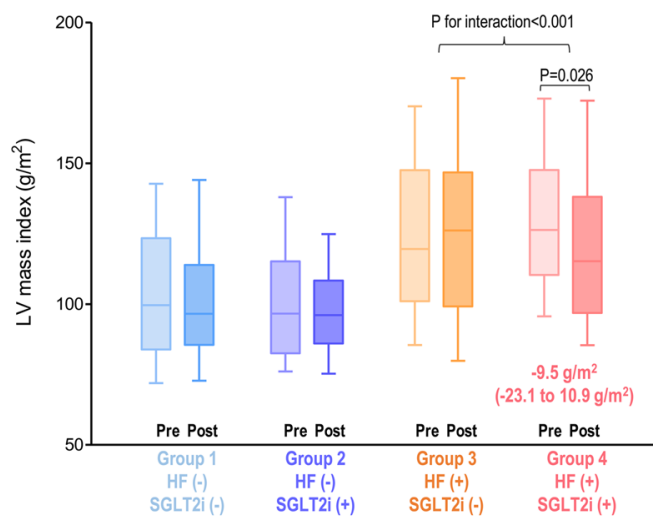

\section{d Changes in LV-GLS}

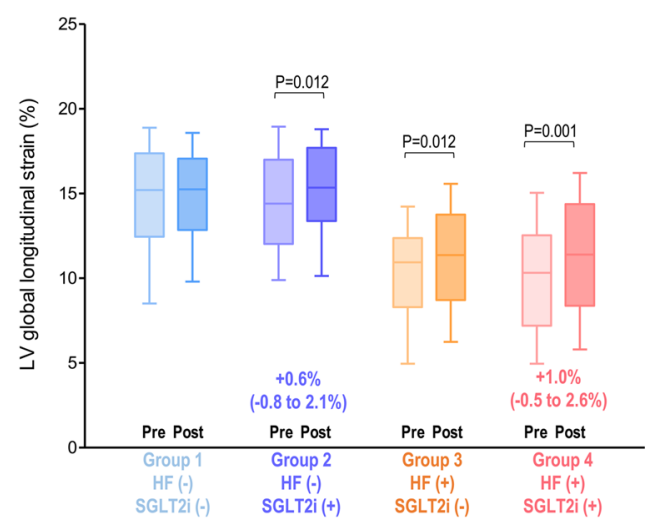

f Changes in PASP

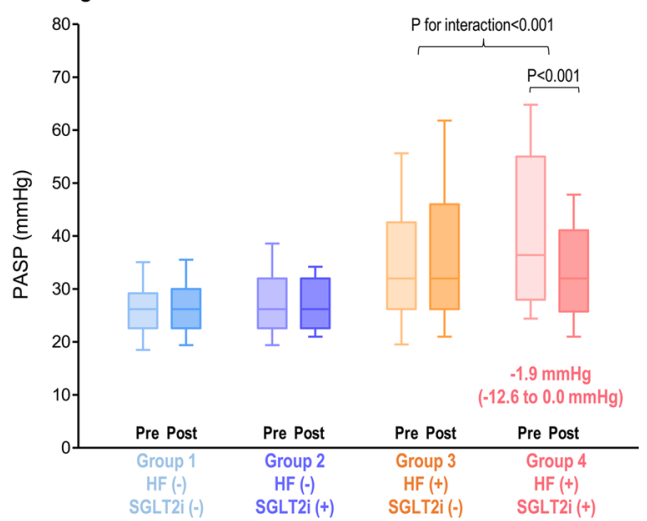

Fig. 2 Changes in LV function and geometry by SGLT2i according to the presence of HF and the use of SGLT2i. Echocardiographic parameters at baseline and follow-up are presented according to the presence of HF and the use of SGLT2i: a LV-EDD, b LV-MI, c LV-EF, d LV-GLS, e mitral E/e' ratio, and $\mathbf{f}$ PASP. Bars represent the median with interquartile range (Q1-Q3). Intra-group and inter-group comparisons were performed with paired t-test generalized linear model for repeated measure analysis, respectively. LV left ventricular, EF ejection fraction, GLS global longitudinal strain, EDD end-diastolic dimension, MI mass index, PASP pulmonary arterial systolic pressure; others as in Fig. 1

diastolic function parameters (Fig. 2). A reduction in mitral E/e' ratio was observed in the group 2 (from 10.6 [9.0-13.5] to $10.5[8.3-14.0] ; \mathrm{p}=0.028)$ and group 4 (from 15.6 [11.9-24.3] to 13.0 [9.1-19.1]; $\mathrm{p}<0.001$ ), but not observed in those without SGLT2i treatment (groups 1 and 3) (Fig. 2e). The group 4 patients also showed a significant decrease in PASP (from 36.4 [28.0-54.0] to 
Table 2 Multivariate analysis for the improvement in LV-EF

\begin{tabular}{|c|c|c|c|c|c|c|}
\hline & \multicolumn{3}{|c|}{$+5 \%$ improvement in LV-EF } & \multicolumn{3}{|c|}{$+10 \%$ improvement in LV-EF } \\
\hline & Adjusted OR & $95 \% \mathrm{Cl}$ & p-value & Adjusted OR & $95 \% \mathrm{Cl}$ & $p$-value \\
\hline Age (per +1 year) & 0.965 & $0.937-0.993$ & 0.015 & 0.975 & $0.949-1.002$ & 0.070 \\
\hline Male sex & - & - & - & 0.271 & $0.125-0.584$ & 0.001 \\
\hline Hypertension & 0.521 & $0.278-0.975$ & 0.042 & - & - & - \\
\hline SGLT2i & 2.384 & $1.266-4.488$ & 0.007 & 2.236 & $1.106-4.521$ & 0.025 \\
\hline $\begin{array}{l}\text { Standard dose of beta-block- } \\
\text { ers for } \mathrm{HF}^{\mathrm{a}}\end{array}$ & - & - & - & 2.849 & $1.126-7.205$ & 0.027 \\
\hline LV-EDV (per +1 mL) & 0.987 & $0.977-0.996$ & 0.007 & - & - & - \\
\hline LV-EF (per +1\%) & 0.919 & $0.891-0.948$ & $<0.001$ & 0.928 & $0.906-0.950$ & $<0.001$ \\
\hline PASP $($ per $+1 \mathrm{mmHg})$ & 1.025 & $1.000-1.051$ & 0.049 & - & - & - \\
\hline
\end{tabular}

Multivariate logistic regression analysis was performed in the total study population. Univariate factors with $p$-values $<0.200$ entered the multivariate analysis, using stepwise backward elimination methods to select the factors for inclusion in the multivariable analysis

$L V$ left ventricular, EF ejection fraction, OR odds ratio, $C I$ confidence interval, HTN hypertension, SGLT2i sodium-glucose cotransporter 2 inhibitor, EDV end-diastolic volume, PASP pulmonary artery systolic pressure

a Standard doses of beta-blockers for HF were determined according to the 2016 ESC Guidelines for the diagnosis and treatment of acute and chronic heart failure [6]

$32.0 \mathrm{mmHg}$ [26.2-41.0]; $\mathrm{p}<0.001)$, but not in the group 3 patients ( $p$ for interaction $<0.001$ ) (Fig. $2 f$ ).

There was no difference in the changes in echocardiographic parameters according to the type of SGLT2i (dapagliflozin vs. empagliflozin; Additional file 1: Figures S1 and S2).

\section{Comparison of LV function changes between HFrEF and $\mathrm{HFpEF}$}

In patients with HFrEF (LV-EF $<40 \%)$, the LV systolic function parameters showed significant improvement in those with SGLT2i treatment ( $\triangle \mathrm{LV}$-EF, $+8.8 \%$ [3.0-17.9]; $\Delta$ LV-GLS, $+1.7 \%$ [0.1-3.5]), but not in those without SGLT2i treatment $(\mathrm{p}<0.001$ for both LV-EF and LV-GLS) (Fig. 3). Of note, the changes in LV-EF and LV-GLS did not show different according to the SGLT2i treatment in HFpEF patients.

Similar patterns were observed for LV geometry and diastolic function. The HFrEF patients with SGLT2i treatment showed significant decreases in LV-EDD, LV-EDV, mitral E/e' ratio and PASP, whereas the improvements in LV geometry and diastolic function were not observed in the HFpEF patients with SGLT2i treatment (Fig. 3).

\section{Changes in NT-proBNP levels}

We compared the changes in NT-proBNP levels in patients with both baseline and follow-up measurement $(\mathrm{n}=76)$ (Fig. 4a). The HF patients with SGLT2i treatment (group 4) showed a significant decrease in NTproBNP levels (from 1819.6 [547.3-5695.4] to $782.1 \mathrm{pg} /$ $\mathrm{mL}$ [181.5-2954.0]; $\mathrm{p}=0.008$ ), but other groups did not ( $\mathrm{p}$ for interaction $=0.028$ between group 4 vs. 3 ).
Among the HF patients with both baseline and followup NT-proBNP measurements $(n=69)$, the reduction in NT-proBNP was observed only in HFrEF patients treated with SGLT2i (from 2202.5 [572.4-6131.4] to $767.5 \mathrm{pg} / \mathrm{mL}$ [183.1-1688.7]; $\mathrm{p}=0.001$ ), but not in the HFrEF patients without SGLT2i ( $\mathrm{p}$ for interaction $=0.035$ between HFrEF with SGLT2i vs. HFrEF without SGLT2i) (Fig. 4b). The HFpEF patients did not show significant changes in NT-proBNP levels regardless of the use of SGLT2i.

\section{Discussion}

In this retrospective cohort study, we observed that the use of SGLT2i was associated with improvements in LV geometry, systolic and diastolic function in type 2 diabetic patients. The improvement in cardiac function by SGLT2i was more prominent in HF patients, compared to the patients without HF. Of note, among the diabetic patients with HF, the improvement in cardiac function was observed in HFrEF patients, but not in HFpEF patients. Our findings provide background for the clinical benefits reported in recent trials, and suggest that the benefits of SGLT2i in HF patients may be more prominent in HFrEF, compared to HFpEF.

\section{Established cardiovascular benefits of SGLT2i and potential mechanisms}

The SGLT2i showed robust evidence for prevention of HF and cardiovascular mortality: a meta-analysis of largescale trials showed that the use of SGLT2i leads to about $30 \%$ reduction in HF hospitalization and cardiovascular mortality in HF patients, and about $20 \%$ reduction in HF hospitalization and cardiovascular mortality in diabetic patients without HF $[1-3,9]$. Because these benefits 


\section{a Changes in LV-EF}

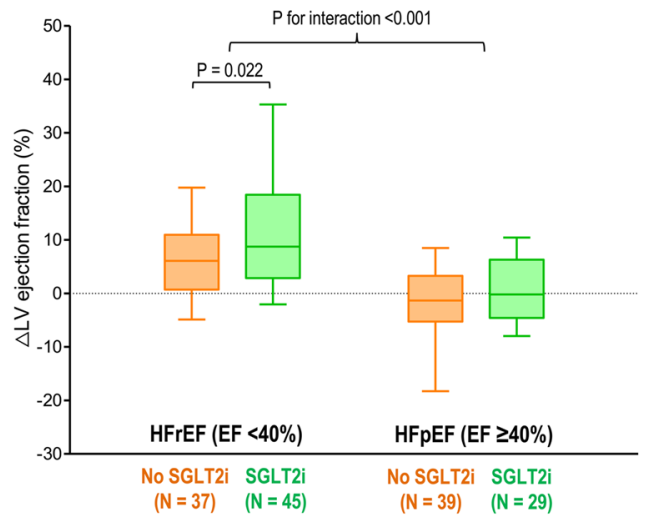

C Changes in LV-EDD

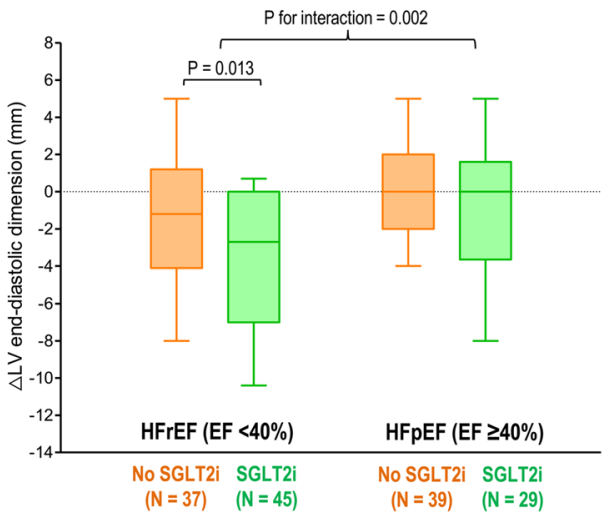

e Changes in mitral E/e' ratio

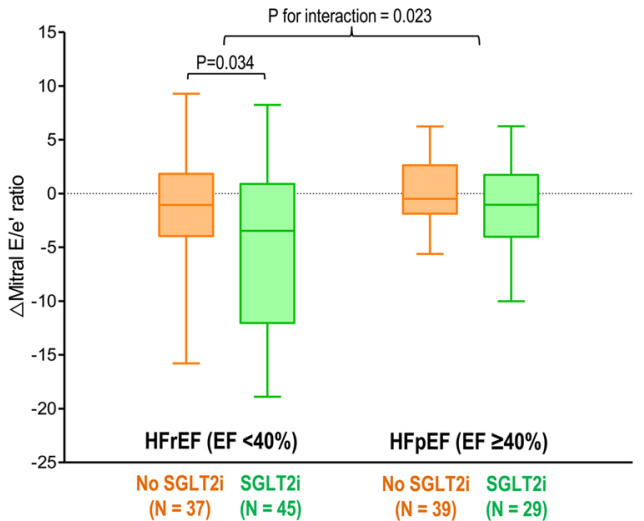

b Changes in LV-GLS

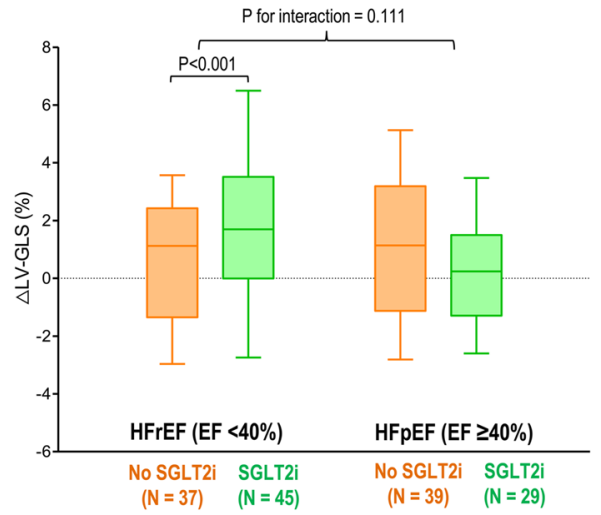

d Changes in LV-EDV

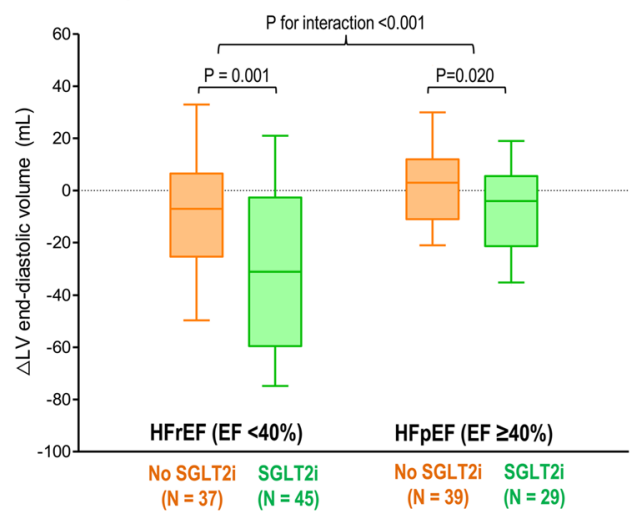

f Changes in PASP

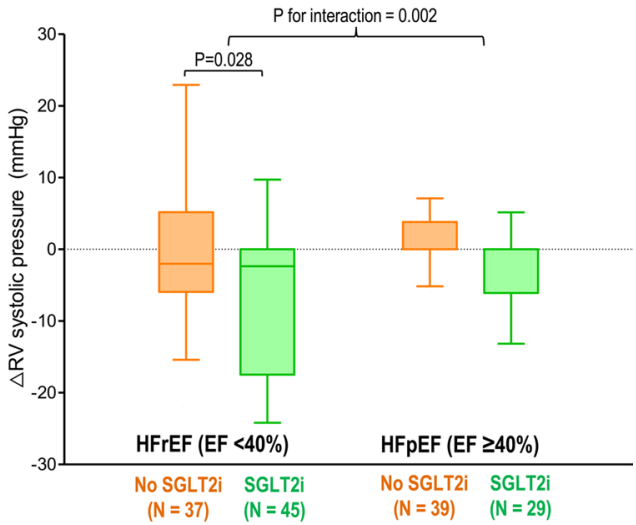

Fig. 3 Changes in LV function and geometry by SGLT2i according to the types of HF. The changes in echocardiographic parameters were compared between subgroups divided according to the types of HF (HFrEF vs. HFpEF) and the use of SGLT2i: a LV-EF, b LV-GLS, c LV-EDD, d LV-EDV, e mitral E/e' ratio, and $\mathbf{f}$ PASP. Bars represent the median with interquartile range (Q1-Q3). Intra-group and inter-group comparisons were performed with paired t-test generalized linear model for repeated measure analysis, respectively. Abbreviations as in Figs. 1 and 2

appeared at early phase of the clinical trials, which cannot be explained by the glucose lowering effect, multiple glucose-independent mechanisms have been suggested.
Most of all, the diuretic effect of SGLT2i would be the key component for HF prevention which is different from those observed with conventional diuretics: (1) SGLT2i 


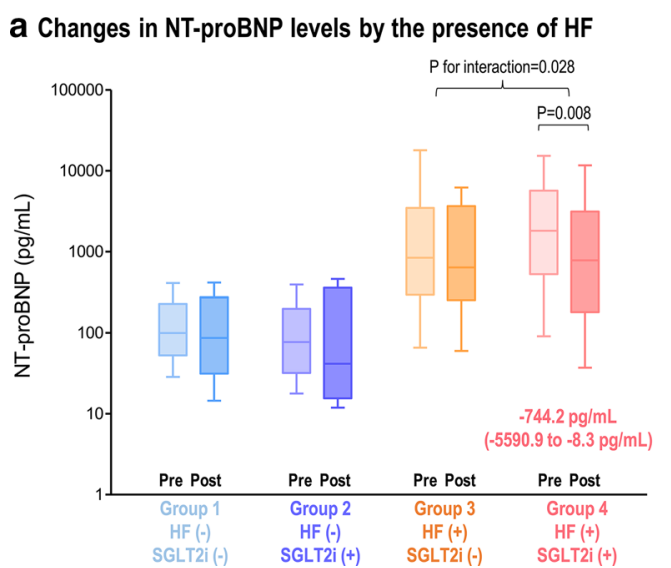

b Changes in NT-proBNP levels by the types of HF

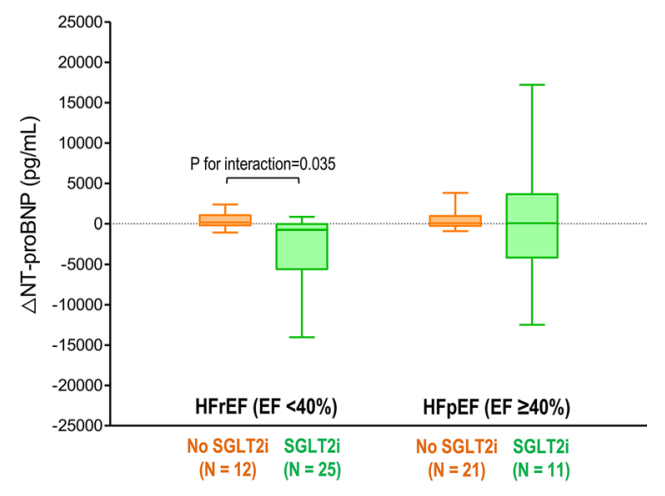

Fig. 4 Changes in NT-proBNP levels by SGLT2i according to the presence and types of HF. The changes in the levels of NT-proBNP were compared according to the use of SGLT2i and the presence of HF (a), and the types of HF (b). Abbreviations: as in Figs. 1 and 2

do not affect plasma osmolarity (2) activates the tubuleglomerular feedback through the increased delivery of fluid and electrolytes to the macula densa, (3) produces a greater fluid clearance from the interstitial space resulting in a better congestion relief with minimal impact on arterial filling and organ perfusion, and (4) exerts renoprotective effects $[4,10,11]$.

In addition, the SGLT2i may provide cardiovascular benefits by an improved myocardial energy metabolism $[4,12]$. The use of SGLT2i results in hyperketonemia, and switches myocardial fuel utilization from glucose to ketone bodies and free fatty acid, resulting in a more efficient ATP production [13, 14]. Also, the SGLT2i can inhibit cardiac $\mathrm{Na}^{+}-\mathrm{H}^{+}$exchanger (NHE), resulting in the reduction of intracellular calcium and an increase of mitochondrial $\mathrm{Ca}^{2+}$, which restores mitochondrial function and redox state, activates ATP production [15]. These potential mechanistic background was further supported by animal model studies: the use of SGLT2i attenuated myocardial oxidative stress and fibrosis in diabetic mice heart, and improved coronary microvascular function and cardiac contractility in pre-diabetic mice model $[16,17]$.

Despite the absence of overt structural heart disease or symptoms of HF, the diabetic patients are considered as "stage A HF" because these patients are at high risk for HF $[5,18]$. These patients often demonstrate subclinical myocardial dysfunction, which can be detected by diastolic dysfunction and LV hypertrophy $[18,19]$. Furthermore, recent studies showed that impaired LV-GLS is a sensitive marker in diabetic patients with stage A HF [20, 21]. In our study, patients without overt HF can be considered as having stages A or B HF due to the presence of diabetes and the impaired LV-GLS values at baseline (LV-GLS $15.2 \%$ in group 1 and $14.6 \%$ in group 2), despite the preserved LV-EF. Given the high risk of HF development as well as the presence of subclinical LV dysfunction, there is a need for effective prevention of LV function deterioration in these patients. Several studies that showed improvements in LV diastolic function and reduction in LV-MI by SGLT2i in diabetic patients without overt HF [22, 23]. Also, a reduction in LV-MI in diabetic patients with coronary artery disease was observed in the Effects of Empagliflozin on Cardiac Structure in Patients with Type 2 Diabetes (EMPAHEART) CardioLink-6 trial [24]. Our findings are consistent with these studies that the use of SGLT2i resulted in small but significant improvements in LV geometry and diastolic function in diabetic patients without overt HF. Adding to this, we observed significant improvements in LV-EF and LV-GLS in diabetic patients without overt HF. These structural changes support the mechanistic background of SGLT2i in terms of the improved myocardial intrinsic function and energetics, and also explain the clinical benefits of SGLT2i for prevention of HF in diabetic patients even at the early stage without structural heart disease or HF symptoms.

\section{Cardioprotective effects of SGLT2i in patients with HF}

The glucose-independent benefits of SGLT2i have been confirmed by recently published clinical trials: according to the DAPA-HF trial, the use of dapagliflozin reduced the composite of worsening HF or cardiovascular death to $27 \%$ in HFrEF patients, and the results were not different between those with diabetes and those without [25]. Also, the Dapagliflozin Effects on Biomarkers, Symptoms and Functional Status in Patients with HF with Reduced Ejection Fraction (DEFINE-HF) trial reported clinically meaningful improvements in HF-related health status or natriuretic peptides in HF patients regardless of the 
presence of diabetes [26]. Therefore, it can be reasonable to assume that the cardiovascular benefits of SGLT2i would be independent to its glucose-lowering effect, as demonstrated in various non-diabetic animal models. Byrne et al. investigated non-diabetic mice subjected to pressure overload and found that the 2-week of empagliflozin treatment preserved LV systolic function, which was sustained ex vivo in the absence of ketones or hemodynamic changes [27]. In a rat model of hypertensive HF, empagliflozin improved LV systolic function, reduced LV cavity size, and attenuated cardiac fibrosis [28]. Recently, Zhang et al. administered dapagliflozin to a pig model of HFpEF and observed that dapagliflozin reduced blood pressure, mitigated LV concentric remodeling, and attenuated hypertension-induced macrovascular inflammatory response [29].

In the present study, we observed more prominent improvements in LV function by SGLT2i in diabetic patients with HF compared to those without, which was independent of the use of cardioprotective medications for HF (ACEi, ARB, beta-blockers, and MRA). Many patients with HF (groups 3 and 4) had uptitration of HF medications during follow-up, and reached the standard dose for optimal HF management. Indeed, we observed that the use of standard dose of beta-blockers for HF was associated with an improved LV-EF among the diabetic patients with HF. More importantly, the use of cardioprotective medications and their changes were not different between those treated with SGLT2i and those without (groups 3 vs. 4), and the improvement of LV function by SGLT2i use was observed even after adjusting for the use of cardioprotective medications and their changes.

\section{Differences in SGLT2i effects between HFrEF vs. HFpEF}

Several studies showed the changes in LV function parameters in diabetic patients according to the types of HF. A retrospective echocardiographic study of diabetic patients on either SGLT2i or DPP-4 inhibitors reported reductions in E/e' ratio and NT-proBNP levels by SGLT2i in patients with $\mathrm{LV}-\mathrm{EF}<40 \%$, but not in those with $\mathrm{LV}-\mathrm{EF} \geq 40 \%$ [30]. However, beneficial effect of SGLT2i has also been suggested in patients with HFpEF: in an echocardiographic study by Soga et al. the mitral E/e' ratio, LV-MI, and LAVI were decreased with dapagliflozin treatment among diabetic patients with high prevalence of HFpEF (69\%) and HFmrEF (17\%), whereas the improvement in LV systolic function and the reduction in BNP levels were minimal [31]. A recent prospective study of diabetic patients with HFpEF demonstrated reductions in E/e' ratio and BNP level, along with improved renal function, decreased fat volumes and reduced oxidative stress [32].
In the present study, we advanced to the comparison of echocardiographic changes by SGLT2 $\mathrm{i}$ in diabetic patients according to the presence and types of HF. The improvements in LV function and geometry were more prominent in HF patients than in those with HF, and these improvements were mainly derived in the HFrEF patients rather than those with HFpEF. Of note, the reduction in NT-proBNP levels was observed only in those with HFrEF patients, in whom the baseline NTproBNP levels were significantly higher compared to the HFpEF patients. These findings are in line with the study by Soga et al. where the levels of BNP were decrease by SGLT2i among those with baseline BNP levels $\geq 100 \mathrm{pg} /$ $\mathrm{mL}$ [31]. These findings suggest that the improvement in cardiac function by SGLT2i would be attributable to the effective volume reduction and possibly to the alleviation of activated neurohormonal axis.

Based on these findings, we suppose that the action mechanisms of SGLT2i can provide possible explanation on the different echocardiographic responses between HFrEF and HFpEF. The levels of natriuretic peptide are higher in HFrEF than in HFpEF, due to the further stretched LV by volume overload and accompanied neurohormonal activation [33, 34]. Several network analysis studies of multiple biomarkers showed that the elevated NT-proBNP is one of the hub of HFrEF pathophysiology $[33,35]$, together with the activated biological pathways for cellular proliferation and cardiac hypertrophy [35]. In contrast, the biomarker studies showed that the main pathophysiology of HFpEF is the inflammation, integrin signaling, and extracellular matrix organization, rather than myocardial stretching characterized by elevated NT-proBNP levels. Therefore, it can be postulated that the use of SGLT2i may exert effective volume reduction effects, which would be more beneficial in HFrEF, but the benefits would be blunted in HFpEF.

However, our study does not necessarily indicate the lack of benefits by SGLT2i in HFpEF, and our findings should be interpreted with caution. Our results would be enough to explain the benefit of SGLT2i in HFrEF in terms of HF prevention, but not sufficient to insist the lack of SGLT2i-induced benefits in HFpEF. At least, given the underlying pathophysiology of HFrEF and HFpEF, we suppose that the benefits of SGLT2i in HFpEF patients would be smaller than those in HFrEF patients. Ongoing clinical trials will provide more concrete evidence for the effects of SGLT2i in HFpEF.

\section{Limitations}

Our study has several limitations. First, our study was a single-center retrospective analysis without pre-specified schedules for echocardiography. Instead, we performed propensity score matching which was successful in terms 
of comorbidities, medications, and follow-up intervals. Also, the statistical power was acceptable for addressing the changes in echocardiographic parameters in the given sample size. Nonetheless, interpretation of our results needs caution due to the innate limitations of a retrospective study. Second, the diagnosis of HF was based on the information available through medical records, which reflected usual practice. However, the definition of HF in the study was not different from the clinical guidelines $[5,6]$. Third, we did not observe comparative benefits of SGLT2i on renal outcomes or glycemic control, which were reported in recent trials [36, 37]. We assume that the lack of renal benefits in our study would be due to the small number of study population and the lack of prespecified schedules for measurements. Finally, we did not investigate the in-depth mechanisms of SGLT2i, and therefore, the mechanistic interpretations of our findings are mainly speculations. While the improvements in LV function by SGLT2i in our study support the cardiovascular benefits of SGLT2i, future studies are required to clarify the biological basis for the effects of SGLT2i on HF.

\section{Conclusion}

In this retrospective cohort study, the use of SGLT2i improved LV systolic and diastolic function, as well as LV geometry, in diabetic patients regardless of the presence of HF. The improvement in LV function was more prominent in those with HFrEF patients compared to those with HFpEF or those without HF. These effects of SGLT2i may contribute to the reduction in HF morbidity and mortality in diabetic patients.

\section{Supplementary information}

Supplementary information accompanies this paper at https://doi. org/10.1186/s12933-020-01042-3.

Additional file 1. Additional tables and figures.

\section{Abbreviations}

Cl: Confidence interval; EF: Ejection fraction; GLS: Global longitudinal strain; HF: Heart failure; HFrEF: Heart failure with reduced ejection fraction; HFpEF: Heart failure with preserved ejection fraction; HR: Hazard ratio; LV: Left ventricle; SGLT2i: Sodium-glucose cotransporter 2 inhibitor.

\section{Acknowledgements}

None.

\section{Authors' contributions}

Conception of research idea and study design: ICH, GYC, YEY; data acquisition: ICH, YEY, JJP, GYC; data analysis and interpretation: ICH, GYC, YEY, JJP, JBP, SPL, HKK, YJK, DWS; statistical analysis: ICH, GYC; supervision and mentorship: GYC, SPL, HKK, YJK, DWS. Each author contributed important intellectual content for writing the manuscript and accepts accountability for the overall work by confirming that questions pertaining to the accuracy or integrity of any portion of the work have been appropriately investigated and resolved. All authors read and approved the final manuscript.
Funding

None.

\section{Availability of data and materials}

The datasets used and/or analyzed during the current study are available from the corresponding author on reasonable request.

\section{Ethics approval and consent to participate}

The study was approved by the Clinical Research Institute of Seoul National University Bundang Hospital (approved on March 11 2019; IRB No. B-1903531-105). Because of the retrospective study design without randomization or intervention, the requirement of informed consent for each individual was waived by the institutional review board.

\section{Consent for publication}

Goo-Yeong Cho, the corresponding author, confirms that this study has been reported honestly, accurately, and transparently. All authors read and approved the final manuscript.

\section{Competing interests}

The authors declare that they have no competing interests.

\section{Author details}

${ }^{1}$ Cardiovascular Center and Department of Internal Medicine, Seoul National University Bundang Hospital, Seongnam, Gyeonggi, South Korea. ${ }^{2}$ Department of Internal Medicine, Seoul National University College of Medicine, Seoul, South Korea. ${ }^{3}$ Cardiovascular Center and Department of Internal Medicine, Seoul National University Hospital, Seoul, South Korea.

Received: 20 January 2020 Accepted: 9 May 2020

Published online: 28 May 2020

\section{References}

1. Zinman B, Wanner C, Lachin JM, Fitchett D, Bluhmki E, Hantel S, Mattheus M, Devins T, Johansen OE, Woerle HJ, et al. Empagliflozin, cardiovascular outcomes, and mortality in type 2 diabetes. N Engl J Med. 2015:373(22):2117-28.

2. Neal B, Perkovic V, Mahaffey KW, de Zeeuw D, Fulcher G, Erondu N, Shaw W, Law G, Desai M, Matthews DR, et al. Canagliflozin and cardiovascular and renal events in type 2 diabetes. N Engl J Med. 2017;377(7):644-57.

3. Wiviott SD, Raz I, Bonaca MP, Mosenzon O, Kato ET, Cahn A, Silverman MG, Zelniker TA, Kuder JF, Murphy SA, et al. Dapagliflozin and cardiovascular outcomes in type 2 diabetes. N Engl J Med. 2019;380(4):347-57.

4. Verma S, McMurray JJV. SGLT2 inhibitors and mechanisms of cardiovascular benefit: a state-of-the-art review. Diabetologia. 2018;61(10):2108-17.

5. Yancy CW, Jessup M, Bozkurt B, Butler J, Casey DE Jr, Drazner MH, Fonarow GC, Geraci SA, Horwich T, Januzzi JL, et al. 2013 ACCF/AHA guideline for the management of heart failure: a report of the American College of Cardiology Foundation/American Heart Association Task Force on Practice Guidelines. J Am Coll Cardiol. 2013;62(16):e147-239.

6. Ponikowski P, Voors AA, Anker SD, Bueno H, Cleland JGF, Coats AJS, Falk V, Gonzalez-Juanatey JR, Harjola VP, Jankowska EA, et al. 2016 ESC Guidelines for the diagnosis and treatment of acute and chronic heart failure: The Task Force for the diagnosis and treatment of acute and chronic heart failure of the European Society of Cardiology (ESC)Developed with the special contribution of the Heart Failure Association (HFA) of the ESC. Eur Heart J. 2016:37(27):2129-200.

7. Lang RM, Badano LP, Mor-Avi V, Afilalo J, Armstrong A, Ernande L, Flachskampf FA, Foster E, Goldstein SA, Kuznetsova T, et al. Recommendations for cardiac chamber quantification by echocardiography in adults: an update from the American Society of Echocardiography and the European Association of Cardiovascular Imaging. J Am Soc Echocardiogr. 2015;28(1):1-39.

8. Voigt JU, Pedrizzetti G, Lysyansky P, Marwick TH, Houle H, Baumann R, Pedri S, Ito Y, Abe Y, Metz S, et al. Definitions for a common standard for 2D speckle tracking echocardiography: consensus document of the EACVI/ASE/Industry Task Force to standardize deformation imaging. J Am Soc Echocardiogr. 2015;28(2):183-93. 
9. Zelniker TA, Wiviott SD, Raz I, Im K, Goodrich EL, Bonaca MP, Mosenzon O, Kato ET, Cahn A, Furtado RHM, et al. SGLT2 inhibitors for primary and secondary prevention of cardiovascular and renal outcomes in type 2 diabetes: a systematic review and meta-analysis of cardiovascular outcome trials. Lancet. 2019;393(10166):31-9.

10. Hallow KM, Helmlinger G, Greasley PJ, McMurray JJV, Boulton DW. Why do SGLT2 inhibitors reduce heart failure hospitalization? A differential volume regulation hypothesis. Diabetes Obes Metab. 2018;20(3):479-87.

11. Packer M, Butler J, Filippatos GS, Jamal W, Salsali A, Schnee J, Kimura K, Zeller C, George J, Brueckmann M, et al. Evaluation of the effect of sodium-glucose co-transporter 2 inhibition with empagliflozin on morbidity and mortality of patients with chronic heart failure and a reduced ejection fraction: rationale for and design of the EMPEROR-Reduced trial. Eur J Heart Fail. 2019;21:1270-8.

12. Santos-Gallego CG, Requena-lbanez JA, San Antonio R, Ishikawa K, Watanabe S, Picatoste B, Flores E, Garcia-Ropero A, Sanz J, Hajjar RJ, et al. Empagliflozin ameliorates adverse left ventricular remodeling in nondiabetic heart failure by enhancing myocardial energetics. J Am Coll Cardiol. 2019;73(15):1931-44.

13. Mudaliar S, Polidori D, Zambrowicz B, Henry RR. Sodium-glucose cotransporter inhibitors: effects on renal and intestinal glucose transport: from bench to bedside. Diabetes Care. 2015;38(12):2344-53.

14. Yurista SR, Sillje HHW, Oberdorf-Maass SU, Schouten EM, Pavez Giani MG, Hillebrands JL, van Goor H, van Veldhuisen DJ, de Boer RA, Westenbrink BD. Sodium-glucose co-transporter 2 inhibition with empagliflozin improves cardiac function in non-diabetic rats with left ventricular dysfunction after myocardial infarction. Eur J Heart Fail. 2019;21(7):862-73.

15. Baartscheer A, Schumacher CA, Wust RC, Fiolet JW, Stienen GJ, Coronel $\mathrm{R}$, Zuurbier CJ. Empagliflozin decreases myocardial cytoplasmic $\mathrm{Na}(+)$ through inhibition of the cardiac $\mathrm{Na}(+) / \mathrm{H}(+)$ exchanger in rats and rabbits. Diabetologia. 2017;60(3):568-73.

16. Li C, Zhang J, Xue M, Li X, Han F, Liu X, Xu L, Lu Y, Cheng Y, Li T, et al. SGLT2 inhibition with empagliflozin attenuates myocardial oxidative stress and fibrosis in diabetic mice heart. Cardiovasc Diabetol. 2019;18(1):15.

17. Adingupu DD, Gopel SO, Gronros J, Behrendt M, Sotak M, Miliotis T, Dahlqvist U, Gan LM, Jonsson-Rylander AC. SGLT2 inhibition with empagliflozin improves coronary microvascular function and cardiac contractility in prediabetic ob/ob(-/-) mice. Cardiovasc Diabetol. 2019;18(1):16.

18. From AM, Scott CG, Chen HH. The development of heart failure in patients with diabetes mellitus and pre-clinical diastolic dysfunction a population-based study. J Am Coll Cardiol. 2010;55(4):300-5.

19. Mochizuki Y, Tanaka H, Matsumoto K, Sano H, Toki H, Shimoura H, Ooka J, Sawa T, Motoji Y, Ryo K, et al. Clinical features of subclinical left ventricular systolic dysfunction in patients with diabetes mellitus. Cardiovasc Diabetol. 2015;14:37.

20. Ernande L, Bergerot C, Rietzschel ER, De Buyzere ML, Thibault H, Pignonblanc PG, Croisille P, Ovize M, Groisne L, Moulin P, et al. Diastolic dysfunction in patients with type 2 diabetes mellitus: is it really the first marker of diabetic cardiomyopathy? J Am Soc Echocardiogr. 2011;24(11):1268-75.

21. Ernande L, Bergerot C, Girerd N, Thibault H, Davidsen ES, Gautier Pignon-Blanc P, Amaz C, Croisille P, De Buyzere ML, Rietzschel ER, et al. Longitudinal myocardial strain alteration is associated with left ventricular remodeling in asymptomatic patients with type 2 diabetes mellitus. J Am Soc Echocardiogr. 2014;27(5):479-88.

22. Matsutani D, Sakamoto M, Kayama Y, Takeda N, Horiuchi R, Utsunomiya K. Effect of canagliflozin on left ventricular diastolic function in patients with type 2 diabetes. Cardiovasc Diabetol. 2018;17(1):73.

23. Otagaki M, Matsumura K, Kin H, Fujii K, Shibutani H, Matsumoto H, Takahashi H, Park H, Yamamoto Y, Sugiura T, et al. Effect of tofogliflozin on systolic and diastolic cardiac function in type 2 diabetic patients. Cardiovasc Drugs Ther. 2019;33(4):435-42.

24. Verma S, Mazer CD, Yan AT, Mason T, Garg V, Teoh H, Zuo F, Quan A, Farkouh ME, Fitchett DH, et al. Effect of empagliflozin on left ventricular mass in patients with type 2 diabetes and coronary artery disease: The EMPA-HEART CardioLink-6 randomized clinical trial. Circulation. 2019;140:1693-702.

25. McMurray JJV, Solomon SD, Inzucchi SE, Kober L, Kosiborod MN, Martinez FA, Ponikowski P, Sabatine MS, Anand IS, Belohlavek J, et al. Dapagliflozin in patients with heart failure and reduced ejection fraction. N Engl J Med. 2019;381:1995-2008.

26. Nassif ME, Windsor SL, Tang F, Khariton Y, Husain M, Inzucchi SE, McGuire DK, Pitt B, Scirica BM, Austin B, et al. Dapagliflozin effects on biomarkers, symptoms, and functional status in patients with heart failure with reduced ejection fraction: The DEFINE-HF Trial. Circulation. 2019;140(18):1463-76.

27. Byrne NJ, Parajuli N, Levasseur JL, Boisvenue J, Beker DL, Masson G, Fedak PWM, Verma S, Dyck JRB. Empagliflozin prevents worsening of cardiac function in an experimental model of pressure overload-induced heart failure. JACC Basic Transl Sci. 2017;2(4):347-54.

28. Lee HC, Shiou YL, Jhuo SJ, Chang CY, Liu PL, Jhuang WJ, Dai ZK, Chen WY, Chen YF, Lee AS. The sodium-glucose co-transporter 2 inhibitor empagliflozin attenuates cardiac fibrosis and improves ventricular hemodynamics in hypertensive heart failure rats. Cardiovasc Diabetol. 2019;18(1):45.

29. Zhang N, Feng B, Ma X, Sun K, Xu G, Zhou Y. Dapagliflozin improves left ventricular remodeling and aorta sympathetic tone in a pig model of heart failure with preserved ejection fraction. Cardiovasc Diabetol. 2019;18(1):107.

30. Lee SJ, Lee KH, Oh HG, Seo HJ, Jeong SJ, Kim CH. Effect of Sodium-Glucose Cotransporter-2 Inhibitors versus Dipeptidyl Peptidase 4 Inhibitors on Cardiovascular Function in Patients with Type 2 Diabetes Mellitus and Coronary Artery Disease. J Obes Metab Syndr. 2019;28(4):254-61.

31. Soga F, Tanaka H, Tatsumi K, Mochizuki Y, Sano H, Toki H, Matsumoto K, Shite J, Takaoka H, Doi T, et al. Impact of dapagliflozin on left ventricular diastolic function of patients with type 2 diabetic mellitus with chronic heart failure. Cardiovasc Diabetol. 2018;17(1):132

32. Sezai A, Sekino H, Unosawa S, Taoka M, Osaka S, Tanaka M. Canagliflozin for Japanese patients with chronic heart failure and type II diabetes. Cardiovasc Diabetol. 2019;18(1):76.

33. van Sanders Wijk S, van Empel V, Davarzani N, Maeder MT, Handschin R, Pfisterer ME, La Brunner Rocca HP, investigators T-C. Circulating biomarkers of distinct pathophysiological pathways in heart failure with preserved vs. reduced left ventricular ejection fraction. Eur J Heart Fail. 2015;17:1006-14.

34. Miller WL, Mullan BP. Volume overload profiles in patients with preserved and reduced ejection fraction chronic heart failure: are there differences? A pilot study. JACC Heart Fail. 2016;4(6):453-9.

35. Tromp J, Westenbrink BD, Ouwerkerk W, van Veldhuisen DJ, Samani NJ, Ponikowski P, Metra M, Anker SD, Cleland JG, Dickstein K, et al. Identifying pathophysiological mechanisms in heart failure with reduced versus preserved ejection fraction. J Am Coll Cardiol. 2018;72(10):1081-90.

36. Perkovic V, Jardine MJ, Neal B, Bompoint S, Heerspink HJL, Charytan DM, Edwards R, Agarwal R, Bakris G, Bull S, et al. Canagliflozin and renal outcomes in type 2 diabetes and nephropathy. N Engl J Med. 2019;380(24):2295-306.

37. Pollock C, Stefansson B, Reyner D, Rossing P, Sjostrom CD, Wheeler DC, Langkilde AM, Heerspink HJL. Albuminuria-lowering effect of dapagliflozin alone and in combination with saxagliptin and effect of dapagliflozin and saxagliptin on glycaemic control in patients with type 2 diabetes and chronic kidney disease (DELIGHT): a randomised, double-blind, placebocontrolled trial. Lancet Diabetes Endocrinol. 2019;7(6):429-41.

\section{Publisher's Note}

Springer Nature remains neutral with regard to jurisdictional claims in published maps and institutional affiliations. 